\title{
Long-term influence of antihypertensive treatment on arterial stiffness assessed by ambulatory measurement of the QKD interval
}

\author{
Philippe Gosse, Paul Coulon, Georgios Papaioannou and Philippe Lemetayer
}

An increase in arterial stiffness is an important risk factor for cardiovascular events. However, there are few data on the longterm evolution of arterial stiffness in treated hypertensives. We evaluated the progression of arterial stiffness in 120 initially untreated hypertensive patients whose arterial stiffness was assessed by the ambulatory monitoring of the QKD interval measured at baseline and then more than 1 year later. The ambulatory method produced an isobaric index of arterial stiffness, the $Q K D_{100-60}$. Out of these patients, 30 with white coat hypertension did not receive any treatment, and over a mean follow-up period of 5 years their $\mathrm{QKD}_{100-60}$ was unchanged. The 90 other patients received antihypertensive treatment (average of 2.5 classes of drug) over a mean period of 6 years. In this population, the mean $24 \mathrm{~h}$ blood pressure (BP) was significantly reduced $\left(-9 \mathrm{~mm} \mathrm{Hg}\right.$ for systolic BP, $-6 \mathrm{~mm} \mathrm{Hg}$ for diastolic BP) and the $\mathrm{QKD}_{100-60}$ was prolonged $(+3.5 \mathrm{~ms}, P<0.05)$. The presence of type 2 diabetes in 17 of these patients was the sole factor negatively correlated with the improvement in $Q_{K D_{100}} 60$. An initial reduction in $Q K D_{100-60}$ appeared to be a factor of resistance to the BP-lowering action of the medication. Antihypertensive treatment has a long-term action on arterial stiffness. The existence of diabetes appeared to have a negative influence on this improvement. Furthermore, an increase in arterial stiffness may be a factor of resistance to the action of antihypertensive medication.

Hypertension Research (2009) 32, 265-269; doi:10.1038/hr.2009.10; published online 27 February 2009

Keywords: arterial stiffness; antihypertensive treatment; QKD interval

\section{INTRODUCTION}

There are few data on the long-term progression (1 year and above) on arterial stiffness in treated hypertensives. ${ }^{1-5}$ Furthermore, the available data are based on the measurement of the pulse wave velocity ${ }^{6}$ (PWV), which is highly dependent on the blood pressure (BP) at the time of the measurement. A simple decrease in BP for any reason will reduce the PWV by a purely mechanical effect, and this technique cannot easily evaluate alterations in the intrinsic stiffness of the arterial system. Ambulatory measurement of the $\mathrm{QKD}^{7}$ coupled with the ambulatory measurement of BP produces indices of arterial stiffness. The main advantages of this method are that it is completely automatic, that it takes account of instantaneous variations in BP and heart rate $(\mathrm{HR})$ and that it provides a reproducible isobaric index of arterial stiffness. ${ }^{8,9}$ This index has an independent prognostic value in the hypertensive patient ${ }^{10-12}$ and represents a marker of severe progression in systemic sclerosis. ${ }^{13}$ During the follow-up of the Bordeaux cohort of initially untreated hypertensives, we evaluated progression in patients who had benefited from at least two ambulatory measurements of $\mathrm{BP}$ and $\mathrm{QKD}$ separated at least by a 1 year interval.

\section{METHODS}

Population

Patients were recruited from the Bordeaux cohort of hypertensive patients. They had all been referred to our center before receiving antihypertensive treatment and were selected according to the following criteria:

- Office systolic BP (SBP) >140 or diastolic BP (DBP) $>90 \mathrm{~mm} \mathrm{Hg}$ on at least two determinations measured with a mercury sphygmomanometer by a physician after $10 \mathrm{~min}$ sitting or lying.

- Absence of cardiovascular complications or any pathology that might affect the prognosis

- High quality ambulatory measurements of BP and QKD

- Absence of left bundle branch block on the ECG, absence of known thyroid pathology.

All patients gave informed consent for participation in this survey, which was approved by our local ethics committee (Comité de protection des personnes Sud-Ouest et Outre Mer III). After the examination that included the ambulatory measurement of BP, electrocardiogram (ECG) and a full laboratory work-up, the patients were given antihypertensive treatment and followed up by their family physicians who were kept unaware of the QKD results. Some of these patients were not treated as they had normal ambulatory values (daytime 


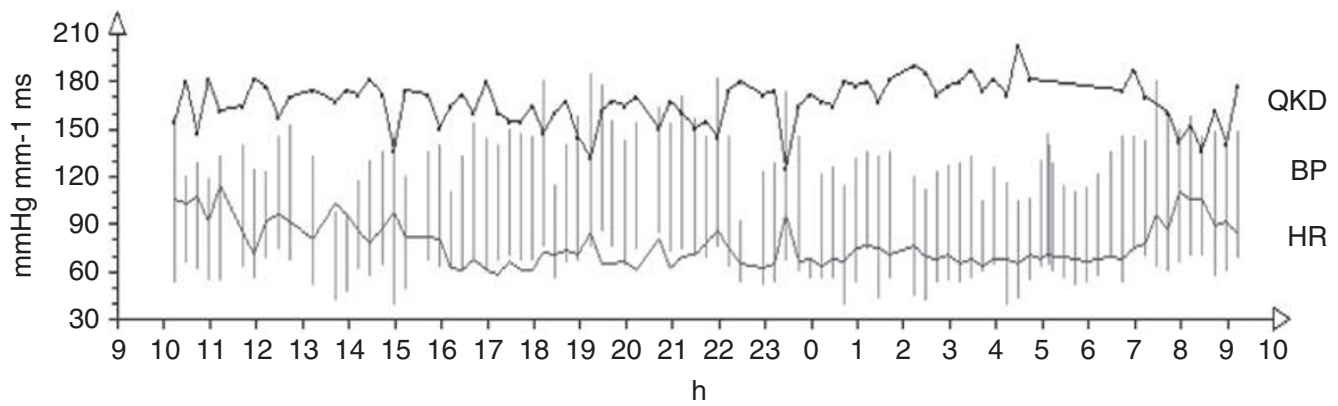

Figure 1 Twenty-four hours ambulatory monitoring of BP and QKD in a patient. The device measures systolic and diastolic BP, HR and QKD every 15 min. From a total of 96 measurements, the software calculates automatically the multiple linear regression of QKD as a function of SBP and HR. The QKD $100-60$ is calculated as a value of QKD for an SBP of $100 \mathrm{~mm} \mathrm{Hg}$ and HR of 60 b.p.m. from the linear regression equation. The software also calculates the theoretical normal value of $\mathrm{QKD}_{100-60}$ according to height from data on a population of normal healthy individuals $\left(<40\right.$ years): $Q K \mathrm{D}_{100-60}=0.73 *$ height $(\mathrm{cm})+91$. The $\mathrm{QKD}_{100-60}$ is thus expressed as a percentage of this theoretical normal value: height-predicted $\mathrm{QKD}_{100-60}=100 * 0 \mathrm{bserved} \mathrm{QKD}_{100-60} / \mathrm{height}$ predicted $\mathrm{QKD}_{100-60}$. BP, blood pressure; HR, heart rate.

SBP $<135 \mathrm{~mm} \mathrm{Hg}$, those with isolated office hypertension or white coat hypertension) in the absence of associated risk factors (diabetes or hypercholesterolemia). Smokers were strongly encouraged to quit. We included in this analysis only those patients, treated or not, who benefited from a second ABPM more than 1 year after inclusion in the cohort.

\section{Ambulatory measurement of BP and QKD interval (Figure 1)}

All patients benefited from ambulatory measurement of BP along with QKD interval. The apparatus (Diasys 200RK, later Diasys Integra, Novacor, France) uses the auscultatory method for measuring BP and determines during each measurement the QKD interval: time between the QRS wave on the ECG and detection of the last Korotkoff sound during deflation of the arm-band. This time is the sum of the pre-ejection time and the time of transmission of the pulse wave from the aortic valves to the microphone placed on the brachial artery. This interval was measured every $15 \mathrm{~min}$ along with $\mathrm{BP}$ over a period of $24 \mathrm{~h}$. From each recording, out of the 96 or so measurements, the software determines automatically, from the multiple linear regression of QKD according to SBP and $\mathrm{HR}$, the value of the $\mathrm{QKD}_{100-60}$, namely the theoretical value of the QKD for a systolic pressure of $100 \mathrm{~mm} \mathrm{Hg}$ and a HR of 60 b.p.m. This index minimizes the influence of the pre-ejection time and enables comparison between patients at a given level of SBP. The value of this parameter is inversely related to PWV and arterial stiffness. The value of $\mathrm{QKD}_{100-60}$ is influenced by the distance between the heart and the point of measurement on the arm and thus by the individual's height. To compare patients and patient groups, the $\mathrm{QKD}_{100-60}$ was expressed as a percentage of the value predicted by height in a population of young normal individuals. ${ }^{14}$

Only patients with at least 80 validated measurements over $24 \mathrm{~h}$ and a negative relationship between QKD and DBP were included in the analysis. A positive relationship between QKD and DBP, found in less than of $5 \%$ of the patients, was indicative of poor detection of Korotkoff sounds by the microphone.

\section{Statistics}

Data were analyzed with SPSS 11.5 software and shown as mean \pm s.d. The patient groups were compared using Student's $t$-test, and the differences between the value on entry and over follow-up were analyzed by paired $t$-tests. A study of the factors linked to mean $24 \mathrm{~h}$ QKD and $\mathrm{QKD}_{100-60}$ evolution was conducted by multiple linear regression including the following variables: age, SBP, DBP, mean HR, and gender, smoking, hypercholesterolemia and diabetes as dummy variables.

\section{RESULTS}

We included in this study 120 patients, of whom 30 had a white coat hypertension and were left untreated. Their main characteristics are listed in Table 1. The patients with white coat hypertension were on average younger and had a lower ambulatory BP than those with

\section{Table 1 Baseline characteristics of population studied}

\begin{tabular}{|c|c|c|c|}
\hline & WCH & Sustained HT & P-value \\
\hline$N$ & 30 & 90 & \\
\hline Male/female & $15 / 15$ & $57 / 33$ & NS \\
\hline Age (years) & $46 \pm 14$ & $52 \pm 14$ & 0.04 \\
\hline Weight (kg) & $70 \pm 12$ & $72 \pm 13$ & NS \\
\hline Height (cm) & $170 \pm 8$ & $170 \pm 10$ & NS \\
\hline Smoker (Y/N) & $5 / 25$ & $24 / 66$ & NS \\
\hline Diabetes $(\mathrm{Y} / \mathrm{N})$ & $0 / 30$ & $10 / 80$ & NS \\
\hline Hypercholesterolemia $(\mathrm{Y} / \mathrm{N})$ & $0 / 30$ & $17 / 73$ & 0.03 \\
\hline Office SBP $(\mathrm{mm} \mathrm{Hg})$ & $149 \pm 10$ & $160 \pm 19$ & 0.004 \\
\hline Office DBP $(\mathrm{mm} \mathrm{Hg})$ & $95 \pm 7$ & $94 \pm 14$ & NS \\
\hline Office HR (b.p.m.) & $73 \pm 13$ & $72 \pm 13$ & NS \\
\hline Day SBP (mm Hg) & $126 \pm 8$ & $144 \pm 16$ & $<0.001$ \\
\hline Day DBP $(\mathrm{mm} \mathrm{Hg})$ & $86 \pm 6$ & $91 \pm 15$ & NS \\
\hline Day HR (b.p.m.) & $82 \pm 12$ & $78 \pm 13$ & NS \\
\hline Night SBP (mm Hg) & $110 \pm 11$ & $124 \pm 17$ & $<0.001$ \\
\hline Night DBP (mm Hg) & $74 \pm 7$ & $78 \pm 14$ & NS \\
\hline Night HR (b.p.m.) & $66 \pm 9$ & $66 \pm 10$ & NS \\
\hline $24 \mathrm{~h} \mathrm{SBP}(\mathrm{mm} \mathrm{Hg})$ & $120 \pm 8$ & $137 \pm 16$ & $<0.001$ \\
\hline $24 \mathrm{~h} \mathrm{DBP}(\mathrm{mm} \mathrm{Hg})$ & $82 \pm 6$ & $87 \pm 15$ & 0.07 \\
\hline 24 h HR (b.p.m.) & $76 \pm 11$ & $74 \pm 12$ & NS \\
\hline $24 \mathrm{~h}$ QKD (ms) & $202 \pm 17$ & $190 \pm 18$ & 0.002 \\
\hline $\mathrm{QKD}_{100-60}(\mathrm{~ms})$ & $216 \pm 16$ & $206 \pm 19$ & 0.009 \\
\hline Height-predicted QKD (\%) & $101 \pm 8$ & $96 \pm 9$ & 0.004 \\
\hline
\end{tabular}

Abbreviations: BP, blood pressure; DBP diastolic BP; HR, heart rate; HT, hypertension; N, no; NS, not significant; SBP, systolic BP; WCH, white coat hypertension; Y, yes.

sustained hypertension. There were few risk factors in this group, which contained only five smokers. All of them stopped smoking during follow-up. Their $\mathrm{QKD}_{100-60}$ was significantly longer than that of the true hypertensive, and when expressed as a percentage of the height-predicted value it was normal $(100 \%)$. The follow-up period was comparable for both groups ( 5 and 6 years respectively). Table 2 lists the changes in BP and HR over $24 \mathrm{~h}$, mean $24 \mathrm{~h}$ QKD and $\mathrm{QKD}_{100-60}$. In the untreated group, we observed a significant increase in mean $24 \mathrm{~h} \mathrm{SBP}$ and DBP with no significant change in $\mathrm{QKD}_{100-60}$. The hypertensive patients received on average 2.5 classes of antihypertensive medication. There was a significant reduction in BP in this group. The mean $24 \mathrm{~h}$ QKD increased significantly by $7 \mathrm{~ms}$, and this increase was significantly and independently correlated with the decrease in mean $24 \mathrm{~h}$ HR $(r=-0.38, P<0.001)$ and the decrease in 
Table 2 BP and QKD changes at follow up

\begin{tabular}{|c|c|c|c|c|c|}
\hline & $W C H, N=30$ & P-value & Sustained $H T, N=90$ & P-value & P-value, $W C H$ vs. SHT \\
\hline Follow up (years) & $5 \pm 4$ & & $6 \pm 4$ & & \\
\hline $24 \mathrm{~h}$ SBP change $(\mathrm{mm} \mathrm{Hg})$ & $+5 \pm 9$ & 0.007 & $-9 \pm 18$ & $<0.001$ & 0.04 \\
\hline 24 h HR change (b.p.m.) & $-1 \pm 7$ & NS & $-4 \pm 10$ & $<0.001$ & NS \\
\hline 24h QKD change (ms) & $-1 \pm 13$ & NS & $+7 \pm 13$ & $<0.001$ & NS \\
\hline QKD $_{100-60}$ change (ms) & $0 \pm 14$ & NS & $+3.5 \pm 16$ & $<0.05$ & NS \\
\hline
\end{tabular}

Abbreviations: BP, blood pressure; DBP, diastolic BP; HR, heart rate; NS, not significant; SBP, systolic BP; WCH, white coat hypertension.

Table 3 Comparison of diabetics and non-diabetic sustained hypertensives

\begin{tabular}{|c|c|c|c|c|}
\hline & \multicolumn{2}{|c|}{ Diabetic } & \multicolumn{2}{|c|}{ Non-diabetic } \\
\hline & Baseline & 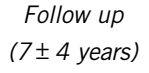 & Baseline & 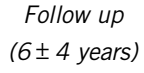 \\
\hline$N$ & 17 & & 73 & \\
\hline Male/female & $13 / 4$ & & $44 / 29$ & \\
\hline Age (years) & $57 \pm 11$ & & $50 \pm 14$ & \\
\hline Weight (kg) & $78 \pm 10$ & & $71 \pm 13$ & \\
\hline Height (cm) & $171 \pm 9$ & & $169 \pm 10$ & \\
\hline Smoker $(\mathrm{Y} / \mathrm{N})$ & $5 / 12$ & & $19 / 54$ & \\
\hline Hypercholesterolemia (Y/N) & $6 / 11$ & & $11 / 62$ & \\
\hline Office SBP (mm Hg) & $170 \pm 23$ & & $156 \pm 18$ & \\
\hline Office DBP (mm Hg) & $92 \pm 17$ & & $94 \pm 14$ & \\
\hline 24 h SBP (mm Hg) & $138 \pm 12$ & $-11 \pm 18$ & $137 \pm 17$ & $-9 \pm 18$ \\
\hline 24 h DBP (mm Hg) & $82 \pm 11$ & $-8 \pm 8$ & $88 \pm 15$ & $-6 \pm 11$ \\
\hline 24 h HR (b.p.m.) & $70 \pm 13$ & $-4 \pm 11$ & $74 \pm 11$ & $-4 \pm 10$ \\
\hline $24 \mathrm{~h}$ QKD (ms) & $184 \pm 17$ & $+3 \pm 13$ & $191 \pm 18$ & $+8 \pm 14$ \\
\hline $\mathrm{QKD}_{100-60}(\mathrm{~ms})$ & $203 \pm 19$ & $-5 \pm 13$ & $207 \pm 19$ & $+5 \pm 16$ \\
\hline Height-predicted $\mathrm{QKD}_{100-60}(\%)$ & $94 \pm 9$ & & $96 \pm 9$ & \\
\hline
\end{tabular}

Abbreviations: BP, blood pressure; DBP, diastolic BP; HR, heart rate; N, no; SBP, systolic BP; Y, yes.

mean 24 h SBP $(r=0.29, P<0.001)$. The $\mathrm{QKD}_{100-60}$ increased significantly $(+3.5 \mathrm{~ms})$, but without reaching the values of the group with white coat hypertension. The change in $\mathrm{QKD}_{100-60}$ was not correlated with the change in mean $24 \mathrm{~h}$ SBP or HR. The only factor negatively correlated with the increase in $\mathrm{QKD}_{100-60}$ was the presence of diabetes $(r=-0.236, P<0.01)$. Seventeen patients in this group had type 2 diabetes in the follow-up period (10 on inclusion and 7 new cases during follow-up). Table 3 compares the diabetic hypertensives with the non-diabetic ones, but in view of the small number of patients involved, no statistical tests were run. The diabetic patients had a lower $\mathrm{QKD}_{100-60}$ than did the non-diabetics, and despite a reduction in mean $24 \mathrm{~h} \mathrm{BP}$ that aligned their values with those of the nondiabetics, their $\mathrm{QKD}_{100-60}$ decreased even lower during the follow up period. Table 4 shows the data of the treated hypertensives as a function of initial value, with normal or initially reduced $\mathrm{QKD}_{100-60}$. Normal arterial stiffness was defined as baseline $\mathrm{QKD}_{100-60}$ exceeding $95 \%$ of the height-predicted value. The baseline mean $24 \mathrm{~h}$ SBP was comparable in both groups, although the mean $24 \mathrm{~h}$ DBP was significantly lower in the group with reduced $\mathrm{QKD}_{100-60}$, indicative of higher pulse pressure. The reduction in mean $24 \mathrm{~h}$ SBP was lower in the group with enhanced arterial stiffness despite the similar antihypertensive treatment. The $\mathrm{QKD}_{100-60}$ increased by $6 \mathrm{~ms}$ in the group
Table 4 Comparison of patients with normal or reduced baseline QKD $_{100-60}$

\begin{tabular}{|c|c|c|c|}
\hline & $\begin{array}{c}\text { Normal } \\
\text { baseline } \\
Q K D_{100-60}\end{array}$ & $\begin{array}{c}\text { Reduced } \\
\text { baseline } \\
Q K D_{100-60}\end{array}$ & $\mathrm{P}$-value \\
\hline$N=$ & 47 & 43 & \\
\hline $\mathrm{QKD}_{100-60}(\mathrm{~ms})$ & $219 \pm 13$ & $191 \pm 12$ & $<0.001$ \\
\hline Height-predicted $\mathrm{QKD}_{100-60}(\%)$ & $102 \pm 5$ & $88 \pm 5$ & $<0.001$ \\
\hline Male/female & $27 / 19$ & $29 / 14$ & NS \\
\hline Age (years) & $46 \pm 13$ & $58 \pm 12$ & $<0.001$ \\
\hline Weight (kg) & $72 \pm 14$ & $73 \pm 13$ & NS \\
\hline Height $(\mathrm{cm})$ & $169 \pm 8$ & $170 \pm 10$ & NS \\
\hline Smoker (Y/N) & $14 / 32$ & $10 / 33$ & NS \\
\hline Diabetes $(\mathrm{Y} / \mathrm{N})$ & $7 / 39$ & $10 / 33$ & NS \\
\hline Hypercholesterolemia (Y/N) & $6 / 40$ & $11 / 32$ & NS \\
\hline Office SBP (mm Hg) & $161 \pm 21$ & $157 \pm 17$ & NS \\
\hline Office DBP (mm Hg) & $99 \pm 13$ & $88 \pm 13$ & $<0.001$ \\
\hline $24 \mathrm{~h}$ SBP $(\mathrm{mm} \mathrm{Hg})$ & $137 \pm 17$ & $137 \pm 15$ & NS \\
\hline $24 \mathrm{~h} \mathrm{DBP}(\mathrm{mm} \mathrm{Hg})$ & $91 \pm 14$ & $81 \pm 13$ & $<0.001$ \\
\hline $24 \mathrm{~h} \mathrm{HR}$ (b.p.m.) & $76 \pm 12$ & $71 \pm 11$ & 0.02 \\
\hline Follow up (years) & $6 \pm 4$ & $6 \pm 4$ & NS \\
\hline Antihypertensive class $(n)$ & 2.5 & 2.5 & NS \\
\hline $24 \mathrm{~h}$ SBP change $(\mathrm{mm} \mathrm{Hg})$ & $-13 \pm 20$ & $-5 \pm 14$ & $<0.05$ \\
\hline $24 \mathrm{~h}$ DBP change $(\mathrm{mm} \mathrm{Hg})$ & $-9 \pm 11$ & $-3 \pm 9$ & $<0.01$ \\
\hline 24h HR change (b.p.m.) & $-3 \pm 10$ & $-4 \pm 9$ & NS \\
\hline $24 \mathrm{~h}$ QKD change (ms) & $+5 \pm 13$ & $+10 \pm 13$ & NS \\
\hline $\mathrm{QKD}_{100-60}$ change $(\mathrm{ms})$ & $+1 \pm 15$ & $+6 \pm 17$ & NS \\
\hline
\end{tabular}

Abbreviations: BP, blood pressure; DBP, diastolic BP; HR, heart rate; N, no; NS, not significant; SBP, systolic BP; Y, yes.

with increased arterial stiffness and did not change in the other group, although the difference between the two groups was not significant.

\section{DISCUSSION}

Our study showed that the white coat hypertensives had a normal arterial stiffness that was significantly lower than that of the sustained hypertensives. Some studies ${ }^{15}$ based on measuring PWV have shown a significant increase in PWV of white coat hypertensives with respect to normotensives. That is not altogether surprising as the PWV is highly dependent on the value of the BP at the time of its measurement, and under these conditions the PWV and BP will both be elevated in the presence of the physician making the measurement. Ambulatory measurement of the QKD interval not only enables measurement in the absence of a physician, but also provides from a calculation of the $\mathrm{QKD}_{100-60}$ an isobaric index of arterial stiffness whose prognostic value has been shown, independently of the mean $24 \mathrm{~h}$ BP and traditional risk factors. ${ }^{11}$ This method should not be viewed as the 
measurement of stiffness in a muscular artery, but indeed as an estimation of the stiffness in the aorta. The pulse transmission time included in the QKD corresponds to the travel of the pulse wave on an arterial segment, which includes the ascending aorta, transversal aorta (as the device is usually placed on the left arm), subclavian artery and part of the brachial artery. The ascending aorta plays a major role in buffering left-ventricular ejection, and another point of interest in this method is the exploration of this important part of the aorta 'unseen' by the carotid-femoral PWV. As the compliance of muscular arteries such as the brachial artery is unchanged (or even improved) in hypertension, the last part traveled by the pulse is unlikely to explain the reduction of QKD in hypertensive patients and its relationship to cardiovascular events. The QKD interval was shown to be significantly correlated to aortic PWV. ${ }^{16-18}$ These were not very high correlations $(r=0.37-0.55)$, as the QKD interval is influenced by the pre-ejection time and the arterial segments studied by the two methods are not exactly the same. The main interest in the monitoring of QKD is the calculation of $\mathrm{QKD}_{100-60}$. This index allows not only a reduction in the influence of the pre-ejection time but also provides an isobaric index of arterial stiffness that is difficult to compare with PWV, which remains strongly dependent on BP and HR at the time of measurement. In a recent study, Levi et al. ${ }^{19}$ have shown in 147 diabetic patients that $\mathrm{QKD}_{100-60}$ and carotido-femoral PWV were significantly correlated $(r=0.31, P<0.001)$. In this study, $\mathrm{QKD}_{100-60}$ was more strongly correlated with age than PWV, which was influenced by a white coat effect, but $\mathrm{QKD}_{100-60}$ was not.

After around 5 years, the mean $24 \mathrm{~h}$ SBP of the white coat hypertensives increased on average by $5 \mathrm{~mm} \mathrm{Hg}$, confirming the need to monitor these patients if they were not receiving any antihypertensive treatment. In this population with a mean age of 46 years, arterial stiffness did not increase significantly over 5 years, but the sample size was probably too small to show a small change. In a population of 237 normotensive subjects aged 65 years, we observed a significant reduction in $\mathrm{QKD}_{100-60}(-2 \mathrm{~ms})$ over a period of only 2 years. $^{20}$

Antihypertensive treatment was administered to all patients presenting high BP confirmed by ambulatory measurements. With a follow-up of 6 years, these patients received on average 2.5 different antihypertensive agents. The decline in mean $24 \mathrm{~h}$ BP was significant ( $-9 \mathrm{~mm} \mathrm{Hg}$ for SBP, $-6 \mathrm{~mm} \mathrm{Hg}$ for DBP). The increase in mean $24 \mathrm{~h}$ QKD was significantly correlated with the decrease in HR, reflecting the influence of the pre-ejection time on the QKD. ${ }^{21}$ and on the decrease in SBP reflecting, at least in part, the mechanical reduction in PWV secondary to the decrease in $\mathrm{BP}$. The $\mathrm{QKD}_{100-60}$ increased significantly in this population, but its change was not significantly correlated with the reduction in BP. However, it was significantly affected by the presence of diabetes. Diabetes (type 1 or 2) is one of the factors identified as increasing arterial stiffness independently of BP. ${ }^{22-26}$ In our population, 17 of our patients had type 2 diabetes and did not improve their $\mathrm{QKD}_{100-60}$. In fact, they exhibited a reduction despite the significant decrease in BP. This sample is too small to draw definitive conclusions, but this issue merits further investigation. To our knowledge, there are no published studies on the long-term progression of arterial stiffness of diabetics receiving antihypertensive treatment. In the short term (6 months), some studies have shown a significant reduction in PWV with treatment, especially with agents inhibiting the renin-angiotensin system. ${ }^{27} \mathrm{~A}$ comparison of the hypertensives having a normal or reduced $\mathrm{QKD}_{100-60}$ on inclusion in the study showed that those whose arterial stiffness was increased had less lowering of SBP under treatment. This suggests that increased arterial stiffness may be a factor of resistance to the action of antihypertensive agents as hypothesized by Pickering. ${ }^{28}$ Under treatment, patients whose arterial stiffness was raised improved their $\mathrm{QKD}_{100-60}$ significantly, although it did not return to normal. There have been few studies on the long-term progression of arterial stiffness in hypertensive patients. With determinations every 3 months, Ichihara et al. ${ }^{1}$ observed a significant reduction in PWV over 1 year that was independent of the decrease in BP in 71 untreated non-diabetic hypertensives (target $\mathrm{BP}<130 / 85 \mathrm{~mm} \mathrm{Hg}$ ). A similar observation, but over a period of 5 years, was described by Bellido et al. ${ }^{2}$ in 66 initially untreated hypertensives. In the study of Asmar et al., 5 the reduction in PWV over 1 year was comparable in the groups treated with perindopril/indapamide or atenolol, and it could not be attributed to any factor other than the decrease in BP. The study of Mitchell et $a .^{4}$ in 300 patients with coronary artery disease and preserved ejection fraction compared treatment with trandolapril to placebo over a period of 5 years. The carotido-femoral PWV was measured in treated patients, but not at baseline, and was lower in the trandolapril than in the placebo group. Analysis after adjustment for the change in $\mathrm{BP}$ was in favor of an action on the PWV independent of the decrease in BP. Only $11 \%$ of 152 patients randomly allocated to the trandolapril group were diabetic. However, in all these studies on PWV, it is hard to discriminate the influence of the decrease in BP from that of a more direct action on the structure of the arterial wall. Ambulatory measurement of the QKD interval produces automatically an isobaric index (referred to $100 \mathrm{~mm} \mathrm{Hg} \mathrm{SBP}$ ) of arterial stiffness and thus avoids any $a$ posteriori data processing. Our data, along with other published studies, are in favor of long-term improvement in the arterial stiffness of hypertensive patients receiving antihypertensive medication, although without return to normal values.

\section{Limitations of the study}

Our patients were recruited from a cohort whom we have followed up for several years but who are not subject to any therapeutic trial. In these patients, the antihypertensive and antidiabetic treatments were chosen and adjusted by their family physicians. It is unlikely, however, that this influenced our results greatly as the QKD findings were not communicated to their doctors. We could not determine whether any particular class of BP-lowering agent had any better efficacy than another on arterial stiffness. Moreover, we do not know the optimal duration of follow-up to show a therapeutic influence on arterial stiffness. In the short term ( $<6$ months), it is unlikely that treatment would have any significant effect on the structure of the arterial wall, and modifications observed on arterial stiffness assessed by PWV are most likely linked to the simple reduction in distension of the artery. But in the long-term, as here, the effect of treatment competes with the aging process. ${ }^{29}$ and may have minimized the improvement we observed especially in the diabetic patients.

\section{Conclusions}

An increase in arterial stiffness is an important factor for cardiovascular events. ${ }^{30-34}$ Our study indicates that a long-term action on this factor may be obtained by antihypertensive treatment. Other interventions and especially the optimal control of all risk factors, especially diabetes, are doubtless required to slow vascular aging and reduce arterial stiffness, but increased arterial stiffness per se appears to be a factor limiting the efficacy of BP reduction. The limited data in patients with renal insufficiency indicate that improvement in arterial stiffness can improve the prognosis. ${ }^{35}$ Ambulatory measurement of the QKD interval is of value as it provides an indication of arterial stiffness that is independent of the BP at the time of its measurement. 


\section{CONFLICT OF INTEREST}

None of the authors have any conflict of interest in relation with this manuscript.

1 Ichihara A, Hayashi M, Koura Y, Tada Y, Hirota N, Saruta T. Long-term effects of intensive blood-pressure lowering on arterial wall stiffness in hypertensive patients. Am J Hypertens 2003; 16: 959-965.

2 Bellido CA, lavicoli OR, Rusak EJ, Vazquez ST, Pineiro DJ, Lerman J. Continuous improvement of arterial compliance beyond blood pressure decrease after 5 years of antihypertensive treatment. J Clin Hypertens (Greenwich) 2006; 8: 555-560.

3 Kita T, Suzuki Y, Eto T, Kitamura K. Long-term anti-hypertensive therapy with benidipine improves arterial stiffness over blood pressure lowering. Hypertens Res 2005; 28: 959-964.

4 Mitchell GF, Dunlap ME, Warnica W, Ducharme A, Arnold JM, Tardif JC, Solomon SD, Domanski MJ, Jablonski KA, Rice MM, Pfeffer MA. Long-term trandolapril treatment is associated with reduced aortic stiffness: the prevention of events with angiotensinconverting enzyme inhibition hemodynamic substudy. Hypertension 2007; 49: 1271-1277.

5 Asmar RG, London GM, O'Rourke ME, Safar ME. Improvement in blood pressure, arterial stiffness and wave reflections with a very-low-dose perindopril/indapamide combination in hypertensive patient: a comparison with atenolol. Hypertension 2001; 38: 922-926.

6 Laurent S, Cockcroft J, Van Bortel L, Boutouyrie P, Giannattasio C, Hayoz D, Pannier B, Vlachopoulos C, Wilkinson I, Struijker Boudier H. Expert consensus document on arterial stiffness: methodological issues and clinical applications. Eur Heart J 2006; 27: 2588-2605

7 Gosse P, Guillo P, Ascher G, Clementy J. Assessment of arterial distensibility by monitoring the timing of Korotkoff sounds. Am J Hypertens 1994; 7: 228-233.

8 Gosse P, Ansoborlo P, Renaud F, Lemetayer P, Clementy J. Assessment of arterial distensibility by ambulatory monitoring of QKD interval. Reproducibility of the method. Arch Mal Coeur Vaiss 1996; 89: 975-977.

9 Gosse P, Taillard J, Constans J. Evolution of ambulatory measurement of blood pressure and parameters of arterial stiffness over a 1 -year period in patients with systemic sclerosis: ERAMS study. J Hum Hypertens 2002; 16: 627-630.

10 Gosse P, Gasparoux P, Ansoborlo P, Lemetayer P, Clementy J. Prognostic value of ambulatory measurement of the timing of Korotkoff sounds in elderly hypertensives: a pilot study. Am J Hypertens 1997; 10: 552-557.

11 Gosse P, Lasserre R, Minifie C, Lemetayer P, Clementy J. Arterial stiffness evaluated by measurement of the QKD interval is an independent predictor of cardiovascular events. Am J Hypertens 2005; 18: 470-476.

12 Gosse P, Papaioanou G, Coulon P, Reuter S, Lemetayer P, Safar M. Can ambulatory blood-pressure monitoring provide reliable indices of arterial stiffness? Am J Hypertens 2007; 20: 831-838

13 Constans J, Germain C, Gosse P, Taillard J, Tiev K, Delevaux I, Mouthon L, Schmidt C, Granel F, Soria P, Lifermann F, Etienne G, Bonnet F, Zoulim K, Farge-Bancel D, Marie I, Allanore Y, Cabane J, Amonchot A, Macquin-Mavier I, Saves M, Zannad F, Conri C. Arterial stiffness predicts severe progression in systemic sclerosis: the ERAMS study. J Hypertens 2007; 25: 1900-1906.

14 Gosse P, Jullien V, Lemetayer P, Jarnier P, Clementy J. Ambulatory measurement of the timing of Korotkoff sounds in a group of normal subjects: influence of age and height. Am J Hypertens 1999; 12: 231-235.

15 Longo D, Zaetta V, Perkovic D, Frezza P, Ragazzo F, Mos L, Santonastaso M, Garbelotto $R$, Benetos A, Palatini P. Impaired arterial elasticity in young patients with white-coat hypertension. Blood Press Monit 2006; 11: 243-249.

16 Abassade P, Baudouy PY, Gobet L, Lhosmot JP. Comparison of two indices of arterial distensibility: temporal apparitions of Korotkoff sounds and pulse wave velocity.
A Doppler echocardiography and ambulatory blood pressure monitoring study. Arch Mal Coeur Vaiss 2001; 94: 23-30.

17 Abassade P, Baudouy PY, Gobet L, Lhosmot JP. Doppler echocardiographic study of arterial distensibility. Comparison with ambulatory arterial pressure monitoring. Arch Mal Coeur Vaiss 2001; 94: 761-765.

18 Gosse P, Ascher G, Durandet P, Leherisser A, Roudaut R, Dallacchio M. Arterial stiffness: a simple estimation through QKD interval measurement. Med et Hyg 1991; 49: 3288-3289.

19 Levi N, Akakpo S, Estrugo B, Dolbeau G, Maison P, Ajzenberg C, Macquin-mavier I. Arterial stiffness in type 2 diabetic patients: assessment by pulse wave velocity and indices derived from ambulatory blood pressure monitoring. Arch Mal Coeur Vaiss 2007; 100: 34.

20 Gosse P, Roche F, Dauphinot V, Maudoux D, Pichot V, Barthelemy JC. Components of arterial stiffness in a population of 65 year old subjects: PROOF study. J Hypertens 2008; 26: 1138-1146.

21 Gosse P, Bemurat L, Mas D, Lemetayer P, Clementy J. Ambulatory measurement of the QKD interval normalized to heart rate and systolic blood pressure to assess arterial distensibility—value of QKD100-60. Blood Press Monit 2001; 6: 85-89.

22 Giannattasio C, Failla M, Piperno A, Grappiolo A, Gamba P, Paleari F, Mancia G. Early impairment of large artery structure and function in type I diabetes mellitus. Diabetologia 1999; 42: 987-994.

23 Cameron JD, Bulpitt CJ, Pinto ES, Rajkumar C. The aging of elastic and muscular arteries: a comparison of diabetic and nondiabetic subjects. Diabetes Care 2003; 26: 2133-2138.

24 Cruickshank K, Riste L, Anderson SG, Wright JS, Dunn G, Gosling RG. Aortic pulsewave velocity and its relationship to mortality in diabetes and glucose intolerance: an integrated index of vascular function? Circulation 2002; 106: 2085-2090.

25 Salomaa V, Riley W, Kark JD, Nardo C, Folsom AR. Non-insulin-dependent diabetes mellitus and fasting glucose and insulin concentrations are associated with arterial stiffness indexes. The ARIC Study. Atherosclerosis Risk in Communities Study. Circulation 1995; 91: 1432-1443.

26 Schram MT, Henry RM, van Dijk RA, Kostense PJ, Dekker JM, Nijpels G, Heine RJ, Bouter LM, Westerhof N, Stehouwer CD. Increased central artery stiffness in impaired glucose metabolism and type 2 diabetes: the Hoorn Study. Hypertension 2004; 43 : $176-181$.

27 Karalliedde J, Smith A, Deangelis L, Mirenda V, Kandra A, Botha J, Ferber P, Viberti G. Valsartan improves arterial stiffness in type 2 diabetes independently of blood pressure lowering. Hypertension 2008.

28 Pickering TG. Arterial stiffness as a cause of resistant hypertension? J Clin Hypertens (Greenwich) 2007; 9: 390-395.

29 Benetos A, Adamopoulos C, Bureau JM, Temmar M, Labat C, Bean K, Thomas F, Pannier B, Asmar R, Zureik M, Safar M, Guize L. Determinants of accelerated progression of arterial stiffness in normotensive subjects and in treated hypertensive subjects over a 6-year period. Circulation 2002; 105: 1202-1207.

30 Laurent S, Boutouyrie P, Asmar R, Gautier I, Laloux B, Guize L, Ducimetiere P, Benetos A. Aortic stiffness is an independent predictor of all-cause and cardiovascular mortality in hypertensive patients. Hypertension 2001; 37: 1236-1241.

31 Laurent S, Katsahian S, Fassot C, Tropeano Al, Gautier I, Laloux B, Boutouyrie P. Aortic stiffness is an independent predictor of fatal stroke in essential hypertension. Stroke 2003; 34: 1203-1206.

32 Blacher J, Asmar R, Djane S, London GM, Safar ME. Aortic pulse wave velocity as a marker of cardiovascular risk in hypertensive patients. Hypertension 1999; 33: 1111-1117.

33 Blacher J, Guerin AP, Pannier B, Marchais SJ, London GM. Arterial calcifications, arterial stiffness, and cardiovascular risk in end-stage renal disease. Hypertension 2001; 38: 938-942.

34 Blacher J, Guerin AP, Pannier B, Marchais SJ, Safar ME, London GM. Impact of aortic stiffness on survival in end-stage renal disease. Circulation 1999; 99: 2434-2439.

35 Guerin A, Blacher J, Pannier B, Marchais S, Safar A, London GM. Impact of arterial stiffness attenuation on survival of patients in end stage renal failure. Circulation 2001; 103: 987-992. 